\title{
Microstructure Effects on Electrochemical Characteristics for Plasma Spray Deposited $\mathrm{LiFePO}_{4}$ Films
}

\author{
Xuan Zhou ${ }^{1}$, Nick Moroz ${ }^{2}$, Pravansu Mohanty ${ }^{2}$, Fu Bi ${ }^{3}$, Yaping Wang ${ }^{3}$ and B.C. Satishkumar ${ }^{4}{ }^{*}$ \\ ${ }^{1}$ Department of Electrical and Computer Engineering, Kettering University, Flint, MI - 48504, USA \\ ${ }^{2}$ Department of Mechanical Engineering, University of Michigan, Dearborn, MI - 48128, USA \\ ${ }^{3}$ MOE Key Laboratory for Nonequilibrium Synthesis and Modulation of Condensed Matter, School of Science, Xi'an Jiaotong \\ University, Xi'an 710049, China \\ ${ }^{4}$ Advanced Electrification Center, 2400 Village Rd. Ford Motor Co, Dearborn, MI - 48124, USA
}

\begin{abstract}
The electrochemical behavior of composite electrodes used in Li ion batteries is influenced by factors such as microstructural characteristics (e.g. particle size, crystallinity, porosity etc.) and composition. For optimal performance of electrodes these factors are of utmost concern and serve as motivation for research in this field. In this report, we investigated $\mathrm{LiFePO}_{4}$ films synthesized by a novel plasma spray deposition method, which has capability for direct deposition of $\mathrm{LiFePO}_{4}$ films with carbon. This enables electrode characterizations to be carried out at the film level, without recourse to steps involving powder material handling. In this report microstructure and electrochemical properties of $\mathrm{LiFePO}_{4}$ films were investigated to elucidate their unique characteristics. Our studies show that factors such as porosity and microstructure of the films affect the electrochemical properties. The mechanical compression and thermal annealing experiments are shown to affect the electrochemical characteristics of $\mathrm{LiFePO}_{4}$ films. We show that annealing treatment leads to a drastic improvement in impedance and charge-discharge capacities for the $\mathrm{LiFePO}_{4}$ films. These treatments could serve to improve the electrode properties of porous film based materials for $\mathrm{Li}$ ion batteries and help us develop new film based materials for energy storage applications.
\end{abstract}

Received on 05-03-2014 Accepted on 05-05-2014 Published on 25-06-2014

Keywords: Plasma spray, $\mathrm{LiFePO}_{4}$ films, Mechanical compression, thermal annealing, Electrochemical Impedance spectroscopy.

\section{INTRODUCTION}

Li-ion batteries have proven as promising energy storage devices for electric and hybrid electric vehicle (EV and HEV) applications, due to their high energy and power density. However, the traditional electrode fabrication process is a multi-step procedure and involves the synthesis of active electrode material, addition of materials such as conductive carbon and binders, thermal treatment of the final composite under vacuum and final battery assembly. Since each of the steps is a process in its own capacity, the overall process becomes very time intensive and expensive, which severely hinders the acceptance of EVs in the market and limits their growth [1-4]. In recent years, solution precursor plasma spray deposition technique (PSD) has been adopted and investigated in our group to fabricate Li-ion battery materials including both cathode such as $\mathrm{LiCoO}_{2}[5], \mathrm{V}_{2} \mathrm{O}_{5}$ [6] and

*Advanced Electrification Center, 2400 Village Rd. Ford Motor Co, Dearborn, MI - 48124, USA; Tel: (313) 845-0422; Fax: (313) 390-6215;

E-mail: satishbc@gmail.com anode such as $\mathrm{Co}_{3} \mathrm{O}_{4}$ [7]. The initial results are promising and indicate PSD can be used for large scale deposition of electrode materials for Li-ion batteries for industrial use.

The relationship between electrode performance and material microstructure has been intensively investigated for powder based electrodes. The factors such as particle size, porosity, tap density etc. play a vital role in the performance of electrodes, which in turn affect characteristics such as impedance response and cycling behavior [8,9]. For directly deposited film based electrodes, similar investigation will help understand the challenges. In this paper, performance of electrodes based on $\mathrm{LiFePO}_{4}$ film, deposited directly on $\mathrm{Al}$ substrates using plasma spray deposition technique has been investigated and we illustrate microstructure and porosity effects on the electrochemical characteristics of $\mathrm{LiFePO}_{4}$ films through the use of techniques such as EIS and cyclic voltammetry (CV). We have also investigated the effect of mechanical compression and annealing on the electrochemical properties of $\mathrm{LiFePO}_{4}$ films. The mechanical 
compression was carried out to simulate calendar pressing of conventional slurry coated electrodes used in Li ion batteries. Our studies indicate that compression and annealing help to improve electrochemical characteristics of film based $\mathrm{LiFePO}_{4}$ electrodes.

\section{EXPERIMENTAL}

$\mathrm{LiFePO}_{4}$ films with carbon were deposited using plasma spray approach on Al substrates using solution precursors. The details on the synthesis method can be found in the work published elsewhere [6]. To summarize briefly, $\mathrm{LiFePO}_{4}$ films with carbon were deposited through a plasma spray deposition method using solution precursors. The solution precursor consists of $\mathrm{LiOH}, \mathrm{Fe}(\mathrm{II})$ oxalate, ammonium phosphate and carbonizing precursor in homogenized solution. Following the synthesis, microstructure of $\mathrm{LiFePO}_{4}$ films was characterized using scanning and transmission electron microscopy (SEM and TEM) respectively. The microstructure of the films was investigated using Hitachi H2600N SEM and JEOL 2010F TEM. The X-ray diffraction studies of the films were carried out using Rigaku Miniflex diffractometer. The carbon content in $\mathrm{LiFePO}_{4}$ films was characterized using thermogravimetric analysis (TGA) using Q600 thermal analyzer and carbon content was found to be in the range $10-20 \%$. Some of $\mathrm{LiFePO}_{4}$ films were compressed using low ( 60 MPa) and high (300 MPa) compression force under ambient conditions, vacuum annealed in oven at $100^{\circ} \mathrm{C}$ and tested later. Also, we annealed $\mathrm{LiFePO}_{4}$ films in $\mathrm{Ar} / \mathrm{H}_{2}$ flow at $630^{\circ} \mathrm{C}$ for $6-12 \mathrm{hrs}$ and tested. The electrochemical characterizations were carried out using either Solartron 1287 electrochemical interface coupled with Solartron 1255B frequency response analyzer or BioLogic multichannel potentiostat set up. EIS spectra were obtained by scanning in the frequency region 10 $\mathrm{mHz}-1 \mathrm{MHz}$. All the EIS spectra discussed here were measured at open circuit potential. For the electrochemical studies $\mathrm{LiFePO}_{4}$ films served as the working electrode, with $\mathrm{Li}$ foil as the counter and reference electrode. A liquid electrolyte of $1 \mathrm{M}^{\mathrm{L}} \mathrm{LiPF}_{6}$ dissolved in $1: 1$ ethylene carbonate/dimethyl carbonate (EC/DMC) (all from Novolyte Inc) was used along with polypropylene based separator 2500 (from Celgard, USA). The cyclic voltammetry studies were carried out on $\mathrm{LiFePO}_{4}$ films using scanning rate of 0.01 $\mathrm{mV} / \mathrm{sec}$. Galvanostatic charge-discharge studies were carried out using the rate of $0.1 \mathrm{C}$ (10 hours). For battery testing we used the stainless steel flat cells (from MTI Corp., USA). The impedance fitting was done using least squares optimization approach built in Solartron (Zview) or Biologic software.

\section{RESULTS AND DISCUSSION}

\subsection{Impedance Characteristics of $\mathrm{LiFePO}_{4}$ Films}

The XRD pattern in Figure 1a shows the crystalline reflections from $\mathrm{LiFePO}_{4}$ film deposited on Al substrate, which indicate the desired olivine phase. We also show the peaks from JCPDS file for $\mathrm{LiFePO}_{4}$ (card number: 40-1499). In Figure 1b, we compare XRD patterns for as-deposited $\mathrm{LiFePO}_{4}$ film (black graph) with the annealed film (red graph). We notice that $\mathrm{LiFePO}_{4}$ reflections gain intensity after anneal treatment and also we observe the substrate reflections for Al, used for film deposition. The impedance characteristics for as-deposited and annealed $\mathrm{LiFePO}_{4}$ films were investigated. The Nyquist graphs for as-deposited and annealed $\mathrm{LiFePO}_{4}$ films are shown in Figures $\mathbf{2 a}$ and $\mathbf{2} \mathbf{b}$ respectively. The overall impedance spectrum is linear and poorly resolved for as-deposited $\mathrm{LiFePO}_{4}$ film, with no explicit semi-circle feature. However, following the anneal treatment, $\mathrm{LiFePO}_{4}$ film shows an impedance spectrum as shown in Figure $\mathbf{2 b}$. The Nyquist graph in Figure $\mathbf{2 b}$ shows the characteristic semicircle feature, following the anneal treatment at $630^{\circ} \mathrm{C}$ for $6 \mathrm{hr}$. The EIS spectra are fitted to deduce the equivalent circuit parameters conforming to circuit model shown in Figure 2c, which is a typical equivalent circuit model with two RC circuits in series representing two semi-circles. In a typical EIS spectrum an intercept on the $Z^{\prime}$ axis in high frequency corresponds to Ohmic resistance $\left(R_{e}\right)$ of the electrolyte, separator and electrical contacts [10]. The depressed semicircle in the high frequency region represents Li-ion migration resistance $\left(R_{f}\right)$ through the solid electrolyte interphase film formed on the electrode. A second semicircle in the middle frequency range indicates the charge transfer resistance $\left(R_{c t}\right)$. The inclined line in low frequency represents the Warburg impedance (W), which is associated with lithiumion diffusion in the $\mathrm{LiFePO}_{4}$ particles [10]. The values for impedance parameters $R_{f}$ and $R_{c t}$ are listed in Table 1. We notice that $\mathrm{LiFePO}_{4}$ films show drastic improvement in impedance response after the anneal treatment. We suppose the microstructure influences the impedance characteristics of $\mathrm{LiFePO}_{4}$ films. We observe that, $\mathrm{R}_{\mathrm{f}}$ and $\mathrm{R}_{\mathrm{ct}}$ for annealed $\mathrm{LiFePO}_{4}$ film are far lower than from as-deposited $\mathrm{LiFePO}_{4}$ films. This indicates that as-deposited $\mathrm{LiFePO}_{4}$ films exhibit sluggish kinetics, and such a behavior could be attributed to poor ionic conductivity of $\mathrm{LiFePO}_{4}$ films. We show further evidence on film microstructural characteristics to justify our reasoning. We used a one semi-circle model to fit the impedance spectra but high fitting errors indicated its low feasibility.

The plasma spray deposited $\mathrm{LiFePO}_{4}$ films possess a porous microstructure, which is a desired feature for electrodes. However, excess porous structure affects the electrochemical properties of films in an adverse way as shown further. We also studied the effect of compression and annealing on the electrochemical characteristics for $\mathrm{LiFePO}_{4}$ films. In Figure 3 we show the EIS spectra for $\mathrm{LiFePO}_{4}$ films which were subjected to mechanical compression and annealing. The Nyquist graph in Figure 3a shows the impedance response from as-deposited $\mathrm{LiFePO}_{4}$ film. Following the compression using $\sim 60 \mathrm{MPa}$ pressure, we observed changes in the impedance characteristics of $\mathrm{LiFePO}_{4}$ films (see Figure $3 \mathbf{b}$ ). The $\mathrm{LiFePO}_{4}$ film shows reduction in charge-transfer resistance (see Table 2) after compression. We argue that 
(a)

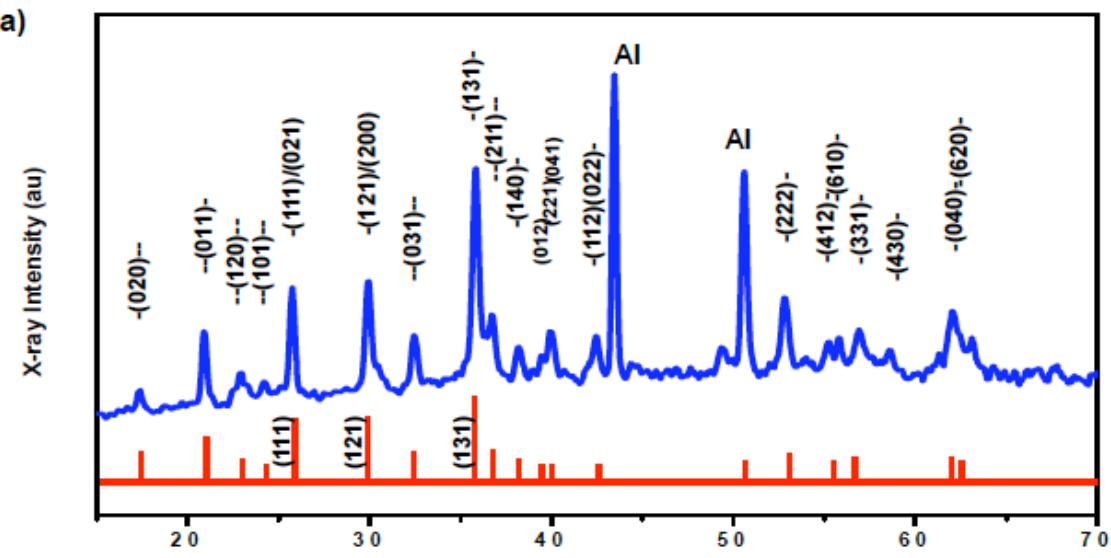

(b)

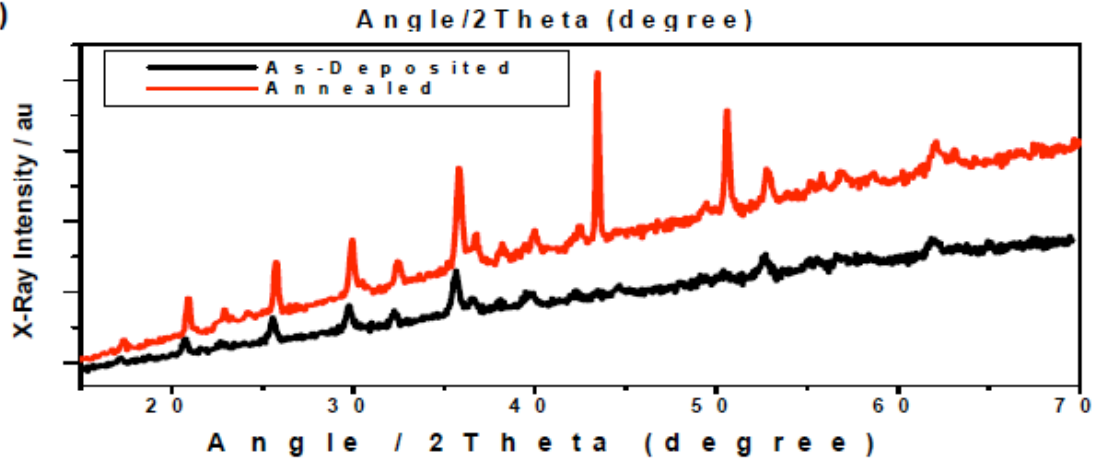

Figure 1: (a) XRD pattern of as deposited $\mathrm{LiFePO}_{4}$ film using plasma spray deposition on Al substrate. (b) shows XRD patterns of as-deposited and annealed (at $630^{\circ} \mathrm{C}$ for $6 \mathrm{hr}$ in $\mathrm{Ar} / \mathrm{H}_{2}$ ) $\mathrm{LiFePO}_{4}$ films.

(a)

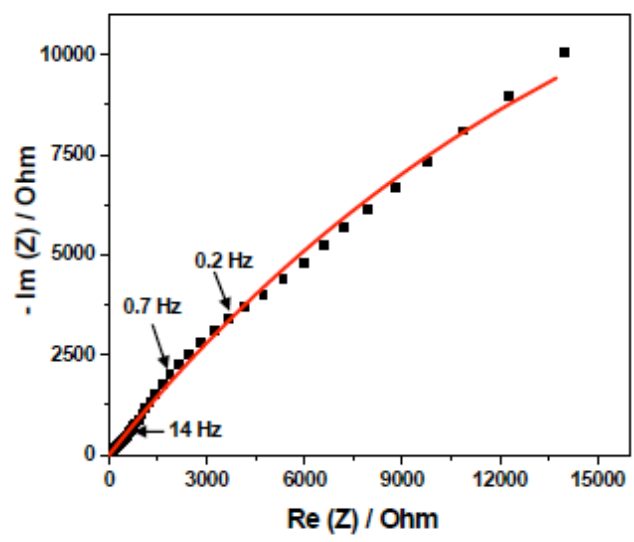

(b)

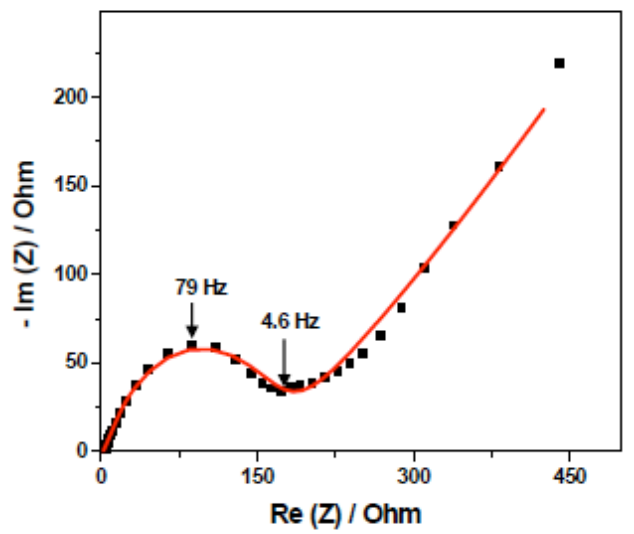

(c)

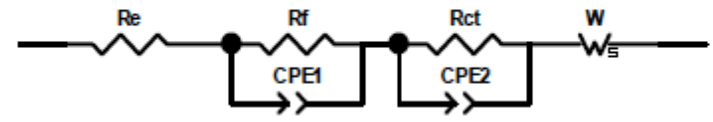

Figure 2: EIS spectrum of (a) plasma spray deposited $\mathrm{LiFePO}_{4}$ film and (b) $\mathrm{LiFePO}_{4}$ film annealed in $\mathrm{Ar} / \mathrm{H}_{2}$ at $630^{\circ} \mathrm{C}$ for $6 \mathrm{hr}$, and (c) the equivalent circuit model with two layers used for fitting the impedance spectra of $\mathrm{LiFePO}_{4}$ films.

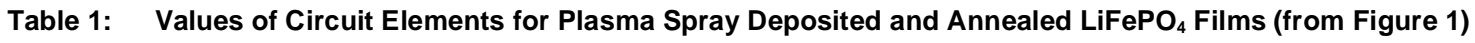

\begin{tabular}{|c|c|c|}
\hline Sample & $\mathbf{R}_{\mathbf{f}}(\Omega)$ & $\mathbf{R}_{\mathrm{ct}}(\Omega)$ \\
\hline \hline As-deposited $\mathrm{LiFePO}_{4}$ film & 5.9 & 14425 \\
\hline Annealed $\mathrm{LiFePO}_{4}$ film & 1.5 & 183.6 \\
\hline
\end{tabular}


(a)

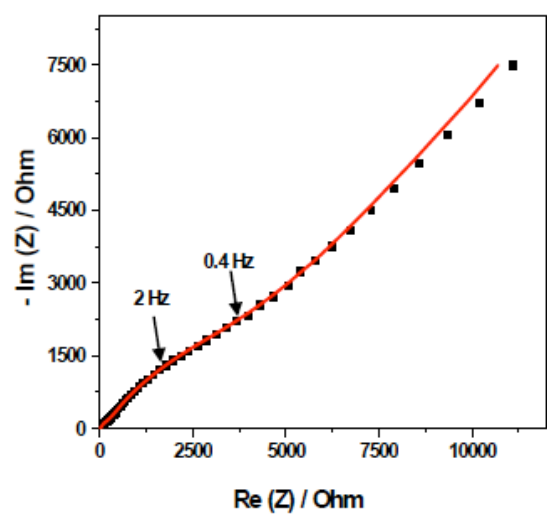

(b)

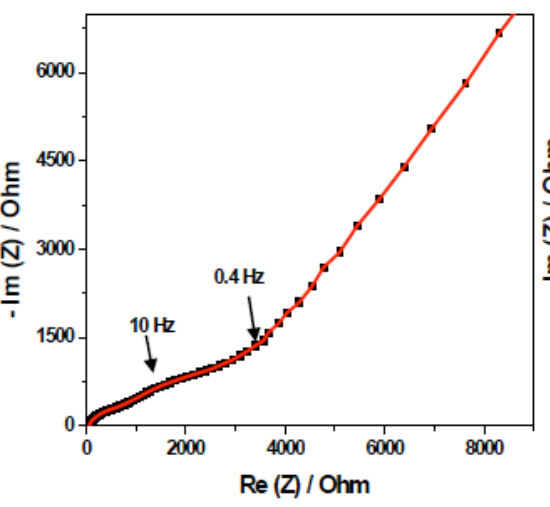

(c)

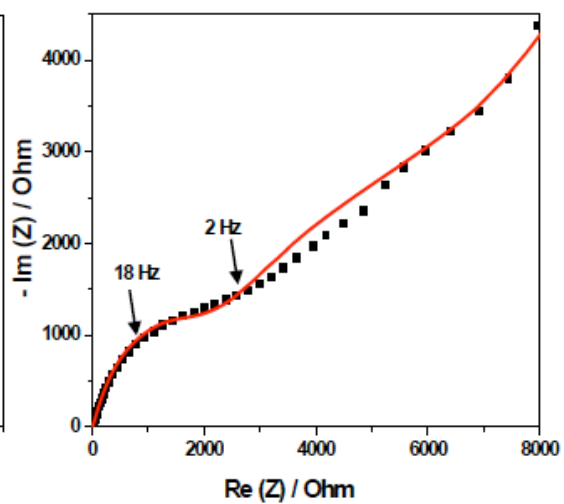

(d)

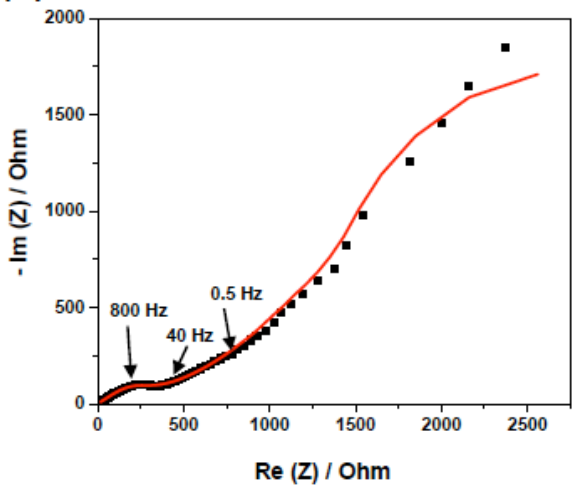

(e)

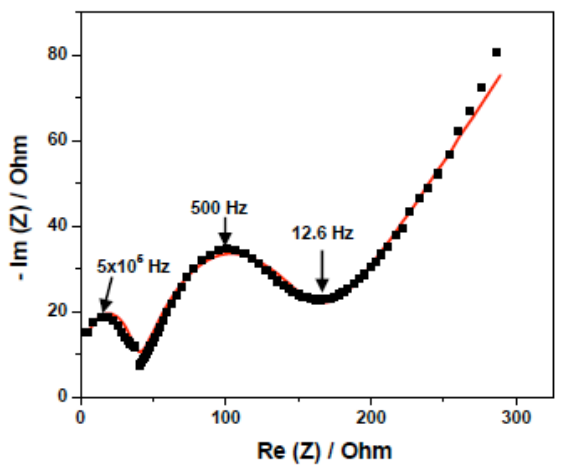

Figure 3: EIS spectra show Nyquist graph of (a) as deposited $\mathrm{LiFePO}_{4}$ film, (b) film compressed using $60 \mathrm{MPa}$ pressure under ambient, (c) $\mathrm{LiFePO}_{4}$ film compressed using $300 \mathrm{MPa}$ pressure under ambient, (d) $\mathrm{LiFePO}$ film annealed at $630^{\circ} \mathrm{C}$ in $\mathrm{Ar} / \mathrm{H}_{2}$ for $6 \mathrm{hr}$ and $($ e) annealed $\mathrm{LiFePO}{ }_{4}$ film $\left(630^{\circ} \mathrm{C}\right.$ in $\mathrm{Ar} / \mathrm{H}_{2}$ for $\left.6 \mathrm{hr}\right)$ after charge-discharge cycling.

Table 2: Values of Circuit Elements for Various LiFePO ${ }_{4}$ Films Subjected to Compression and Annealing Treatment (from Figure 2)

\begin{tabular}{|c|c|c|}
\hline Sample & $\operatorname{Rf}(\Omega)$ & $\operatorname{Rct}(\Omega)$ \\
\hline As-deposited $\mathrm{LiFePO}_{4}$ film & 82.68 & 2618 \\
\hline As-deposited $\mathrm{LiFePO}_{4}$ film / $60 \mathrm{MPa}$ & 452.5 & 2039 \\
\hline As-deposited $\mathrm{LiFePO}_{4}$ film / $300 \mathrm{MPa}$ & 1670 & 2738 \\
\hline Annealed $\mathrm{LiFePO}_{4}$ film & 151.4 & 1586 \\
\hline Annealed \& cycled $\mathrm{LiFePO}_{4}$ film & 39.18 & 110.9 \\
\hline
\end{tabular}

this leads to compaction of porous film electrodes, which is consistent with calendaring process used in battery industry. It is well known that electrodes are typically compressed using calendar press in order to reduce excess porosity, improve active material particle-particle contact and enhance the electrode characteristics. In such studies calendar pressing has been shown to reduce porosity, which in turn affects $\mathrm{Li}$ transport during charge-discharge cycling. However, following the compression using $\sim 300 \mathrm{MPa}$ (see Figure 3c), charge-transfer resistance increases to $2738 \Omega$ as seen in Table 2. This is because, a relatively high compressive pressure could totally seal the pores, which may prevent electrolyte access to interior of the electrode and deteriorates the wetting capability of the electrode.

\subsection{Microstructure Effects on Impedance of $\mathrm{LiFePO}_{4}$ Films}

The effect of compression on the $\mathrm{LiFePO}_{4}$ film microstructure has been investigated using the SEM. The SEM micrographs of as-deposited films before and after compression at $60 \mathrm{MPa}$ are shown in Figures $\mathbf{4 a}$ and $\mathbf{4 b}$ respectively. For the asdeposited films, surface morphology shows a uniform and crack-free microstructure (see Figure 4a). The nanoparticles of $\mathrm{LiFePO}_{4}$ can be seen on the surface and also in the interior of the film. The $\mathrm{LiFePO}_{4}$ nanoparticles form larger aggregates. Following the compression film microstructure shows modifications on the surface, as illustrated in Figure 4b. $\mathrm{LiFePO}_{4}$ nanoparticles are no longer seen as more isolated; instead they seem to have coalesced together in the 
film interior. The film surface shows consolidation of $\mathrm{LiFePO}_{4}$ nanoparticles and porous structure is no more explicit. Thus the use of compression seems to reduce the porous structure of $\mathrm{LiFePO}_{4}$ films and thus enhances the particle-particle contact inside the film microstructure. This in turn helps to improve impedance response from the compressed $\mathrm{LiFePO}_{4}$ films. Alternately, during electrochemical cycling, $\mathrm{Li}$ ions would travel smaller distances between the nanoparticles in the interior of $\mathrm{LiFePO}_{4}$ films. Thus the observed improvement in the impedance characteristics is consistent with the reduced porosity in the films. Our studies indicate that, through the use of compression, excess porosity in plasma spray deposited $\mathrm{LiFePO}_{4}$ films can be reduced and impedance response can be improved. The impedance parameters for circuit elements for as-deposited and compressed $\mathrm{LiFePO}_{4}$ films are listed in Table 2. These studies indicate that porosity plays a significant role on the impedance characteristics of plasma spray deposited $\mathrm{LiFePO}_{4}$ films. A relatively high compression press could potentially seal the tunnels of electrolyte transport, which could adversely affect $\mathrm{Li}$ transport. Thus, an optimized compression is critical for the performance of the battery. In the present studies, plasma spray deposition method yields $\mathrm{LiFePO}_{4}$ films with superfluous porosity and microstructure needs modifications in order to improve the impedance and other electrochemical characteristics.

We also investigated the microstructure of plasma spray deposited $\mathrm{LiFePO}_{4}$ films using transmission electron microscopy. The TEM micrograph of as-deposited films shows presence of $\mathrm{LiFePO}_{4}$ nanoparticles, as illustrated in Figure 4c. The films consist of $\mathrm{LiFePO}_{4}$ nanoparticles in the size range, $30-60 \mathrm{~nm}$. The HRTEM image in Figure $4 \mathbf{d}$ shows $\mathrm{LiFePO}_{4}$ nanoparticles which exhibit a crystalline core morphology (see red circles), and peripheral regions possess amorphous structure. This mixed crystalline-amorphous microstructure seems to be the characteristic of as-deposited $\mathrm{LiFePO}_{4}$ films. The plasma spray deposition process, typically carried out at high temperature, is known to induce residual thermal stresses in the deposited materials [11-13]. This happens due to the fact that, during plasma deposition, rapid cooling of deposited material takes place during the flight inside the plasma plume. Following such a rapid
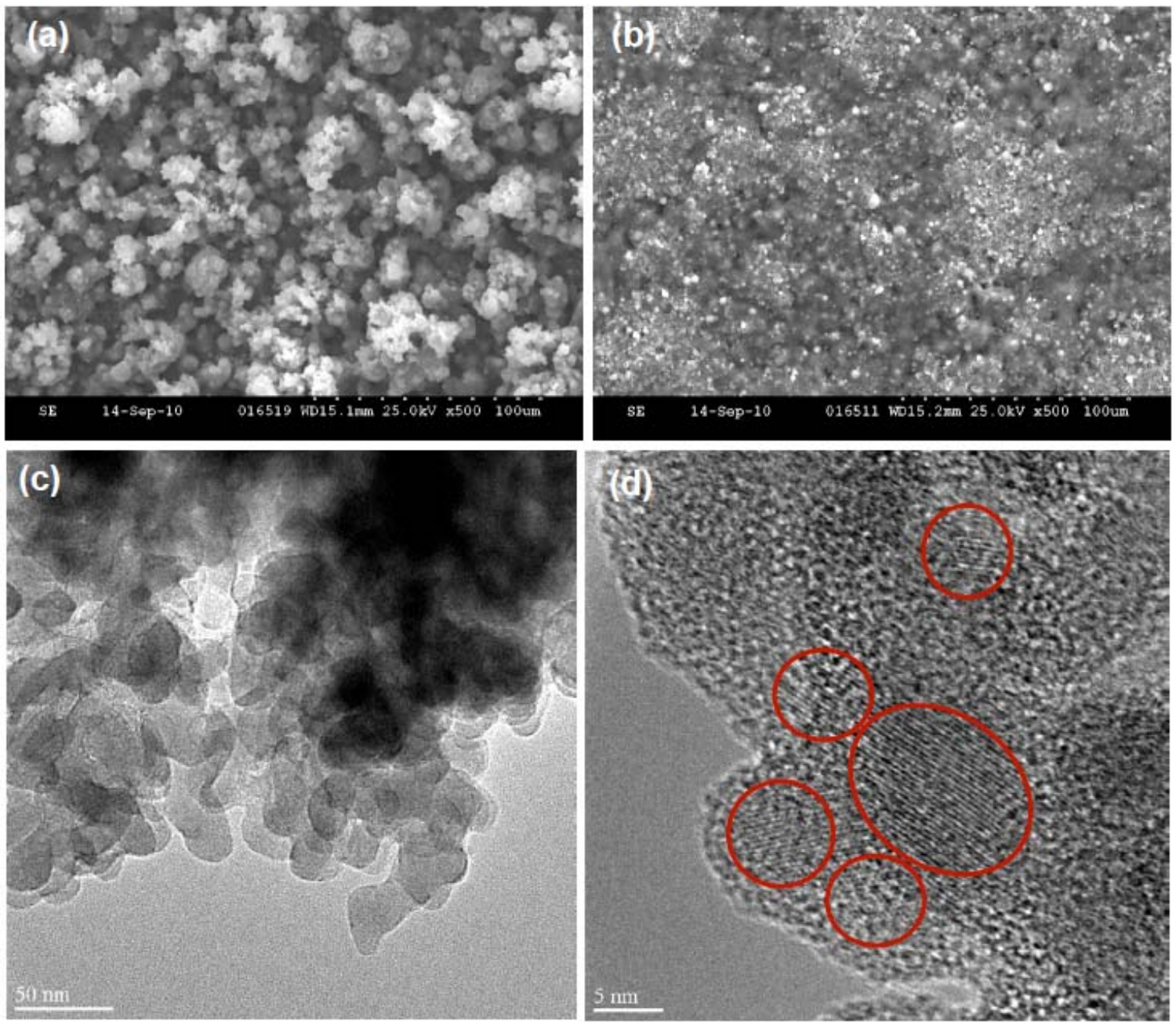

Figure 4: SEM micrographs of $\mathrm{LiFePO}_{4}$ film (a) before and (b) after compression using $300 \mathrm{MPa}$ pressure. The surface morphology shows changes due to compressive force. (c) TEM and (d) HRTEM image of $\mathrm{LiFePO}_{4}$ film with nanoparticles of $\mathrm{LiFePO}_{4}$. The HRTEM image shows the crystalline core regions for $\mathrm{LiFePO}_{4}$ nanoparticles (see red circles) while the outer regions are amorphous. 
cooling, residual stresses are induced in the deposited materials. This in turn leads to the mixed crystallineamorphous microstructure for $\mathrm{LiFePO}_{4}$ films observed in the present studies. Such residual stresses are known to influence the material properties [14-16]. Also, our experiments suggest that $\mathrm{LiFePO}_{4}$ powders collected at farther distance than that used for film deposition show an amorphous structure. This happens because the powders are allowed to cool rapidly in air, while films are deposited on the substrate held closer to plasma gun. The microstructure characteristics discussed above seem to play a major role in the electrochemical properties. In the further section we will show how annealing affects the microstructure and improves film electrochemical properties.

We demonstrated earlier that annealing of $\mathrm{LiFePO}_{4}$ films helped to improve the impedance response as shown in Figure 2. After annealing in $\mathrm{Ar} / \mathrm{H}_{2}$ atmosphere at $630^{\circ} \mathrm{C}$ for 6 hr we observed changes in the microstructure of $\mathrm{LiFePO}_{4}$ films. The HRTEM images of annealed $\mathrm{LiFePO}_{4}$ films are shown in Figures $\mathbf{5 a}$ and $\mathbf{5 b}$ and they illustrate that the microstructure shows modifications. The nanoparticles of $\mathrm{LiFePO}_{4}$ show well resolved crystalline lattice planes and also a layer of carbon was observed around the nanoparticles. The anneal treatment seems to transform the amorphous content in $\mathrm{LiFePO}_{4}$ films and results in uniformly crystalline $\mathrm{LiFePO}_{4}$ nanoparticles covered with carbon, which serves as a conductive layer. The HRTEM image contrast for images of as-deposited and annealed films is obvious in Figures $\mathbf{4 d}$ and $\mathbf{5 b}$. We see segregation of carbon around crystalline $\mathrm{LiFePO}_{4}$ nanoparticles. Following the anneal treatment, impedance response from such annealed $\mathrm{LiFePO}_{4}$ film is shown in Figure $\mathbf{3 d}$. The Nyquist graph shows the semicircle and Warburg contribution to electrode impedance. The EIS spectrum was fitted using the circuit model in Figure 2c and circuit parameters are listed in Table 2. The same $\mathrm{LiFePO}_{4}$ film was subjected to galvanostatic cycling at $0.5 \mathrm{C}$ rate for 30 cycles and impedance spectrum was recorded. The EIS spectrum of annealed $\mathrm{LiFePO}_{4}$ film after chargedischarge cycling is shown in Figure 3e. The Nyquist graph shows two well defined semicircles along with Warburg contribution. The impedance spectrum was fitted to the circuit model (shown in Figure 2c) and circuit parameters are listed in Table 2. These studies indicate that $\mathrm{LiFePO}_{4}$ films obtained by plasma spray deposition exhibit high impedance or poor $\mathrm{Li}$ ion transport kinetics, which is attributed to the porous and mixed crystalline-amorphous microstructure. We assume that amorphous content is responsible for higher impedance in-sprayed $\mathrm{LiFePO}_{4}$ films. However, treatments such as compression and annealing of $\mathrm{LiFePO}_{4}$ films help to reduce the high impedance. We characterized the carbon content in the $\mathrm{LiFePO}_{4}$ films using thermogravimetric analysis. The results of TGA studies are summarized in Figure 6, which show TGA graphs for LiFePO4 films deposited under different conditions. The graphs show weight loss peaks in the temperature range $300-500^{\circ} \mathrm{C}$ due to oxidation of carbon present in the $\mathrm{LiFePO}_{4}$ films. The carbon content in the films in our studies is typically in the range $\sim 15-$ 30 wt.\%. Once again, we emphasize the fact that asdeposited $\mathrm{LiFePO}_{4}$ films have carbon present as shown by TGA analysis. However, after anneal treatment, the carbon develops as a coating layer around the $\mathrm{LiFePO}_{4}$ nanoparticles and clusters (see Figures $\mathbf{5 a}$ and $\mathbf{5 b}$ ). Anneal treatment not only helps improve crystallinity of $\mathrm{LiFePO}_{4}$ films (as shown in Figure 1b), also it helps for consolidation of carbon layer around the $\mathrm{LiFePO}_{4}$ nanoparticles.

During the CV studies on as-deposited films we did not observe the well resolved features representative of oxidation/reduction processes during $\mathrm{Li}$ extraction/insertion
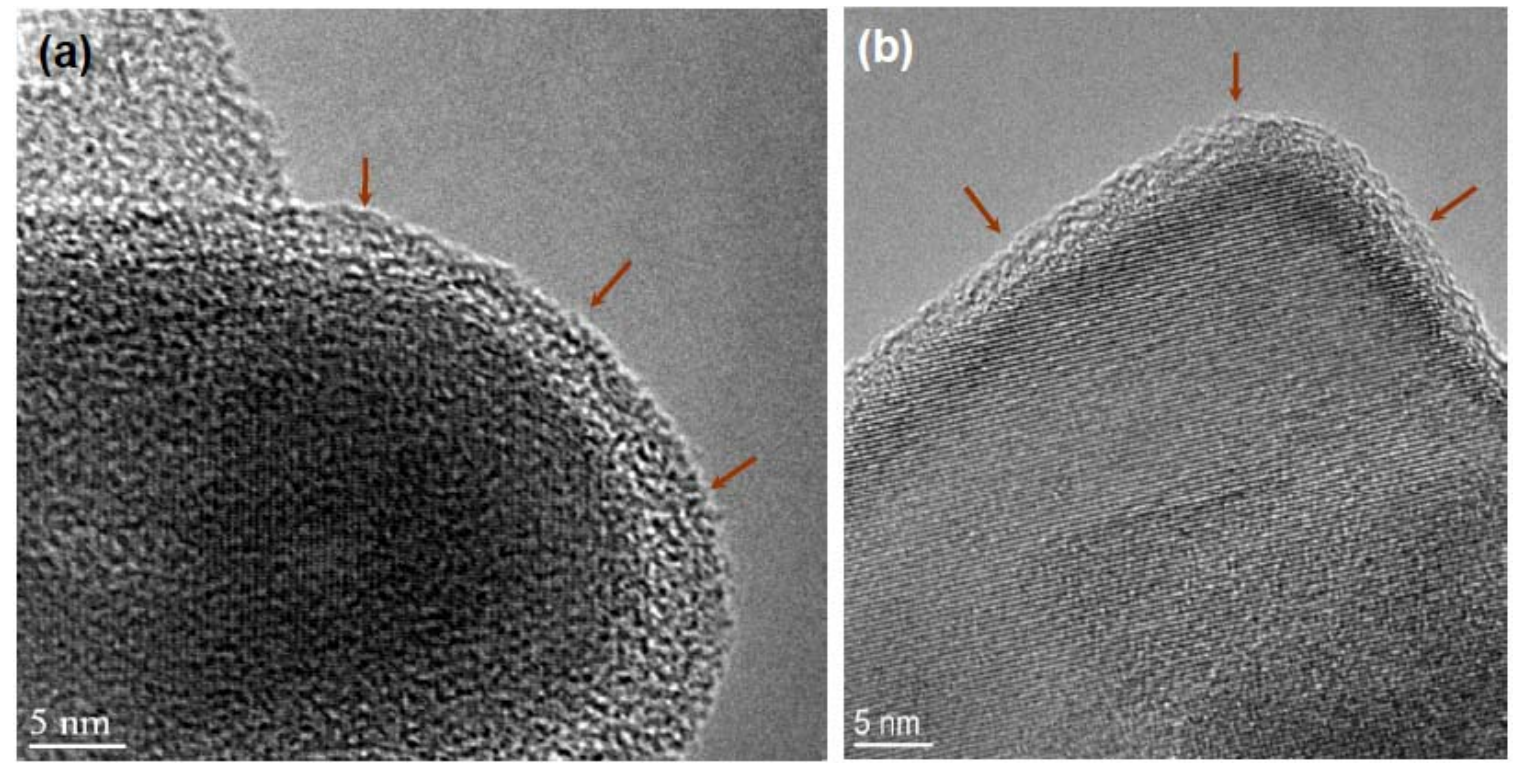

Figure 5: (a) and (b) show HRTEM images of $\mathrm{LiFePO}_{4}$ nanoparticles after the anneal treatment $\left(630^{\circ} \mathrm{C}\right.$ in $\mathrm{Ar} / \mathrm{H}_{2}$ for $\left.6 \mathrm{hr}\right)$. The nanoparticles exhibit a coating with carbon $(2-3 \mathrm{~nm})$ around the crystalline lattice. 


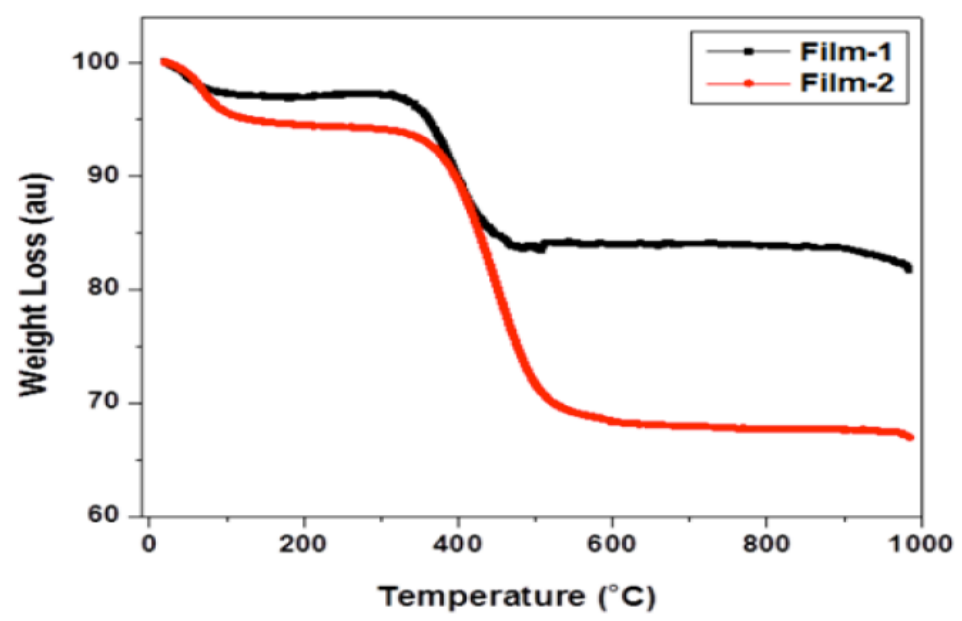

Figure 6: Thermogravimetric weight loss graphs of LiFePO4 films showing the oxidation of carbon.

(a)

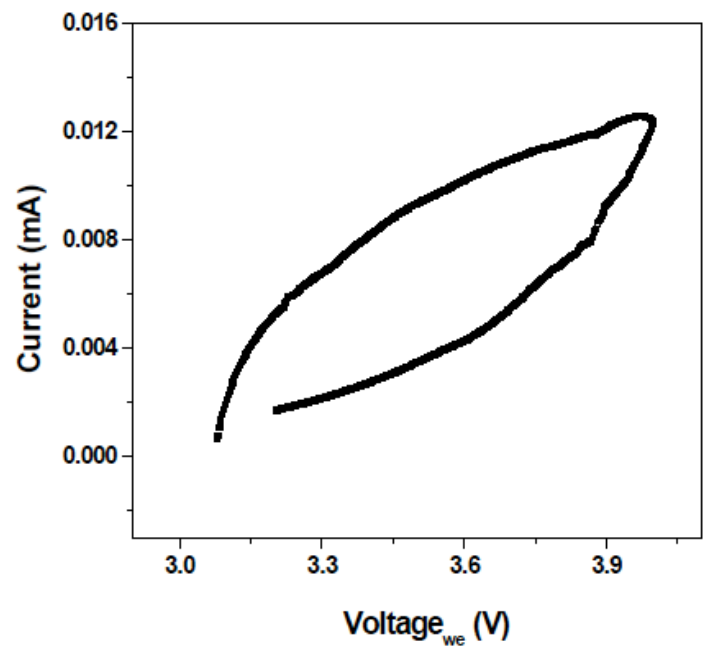

(b)

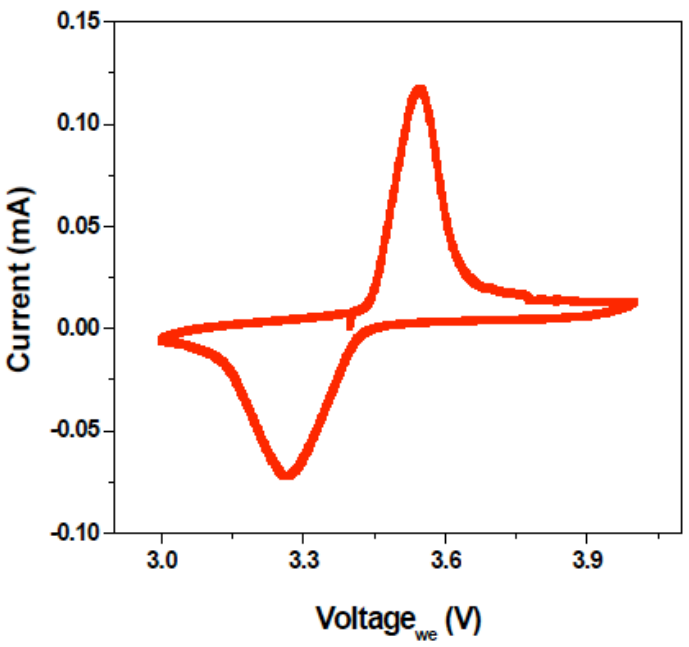

Figure 7: Cyclic voltammograms of (a) as-deposited $\mathrm{LiFePO}_{4}$ film and (b) $\mathrm{LiFePO}_{4}$ film annealed at $630^{\circ} \mathrm{C}$ in $\mathrm{Ar} / \mathrm{H}_{2}$ for $6 \mathrm{hr}$. $\mathrm{Notice}$ the absence of redox peaks in the as-deposited film.

process (see Figure 7a). Our plasma spray deposited $\mathrm{LiFePO}_{4}$ films are fairly porous and even though the XRD shows olivine structure, they exhibit high impedance. As mentioned earlier, microstructure of $\mathrm{LiFePO}_{4}$ films also contributes to the smearing of oxidation/reduction features during the CV scan. We assume that mixed crystallineamorphous microstructure in $\mathrm{LiFePO}_{4}$ films contributes to this effect. Following the annealing treatment, however, the $\mathrm{LiFePO}_{4}$ films show the characteristic peaks due to reversible $\mathrm{Li}$ extraction and insertion, attributed to the reaction, $\mathrm{Li}^{+}+\mathrm{e}^{-}+$ $\mathrm{FePO}_{4} \leftrightharpoons \mathrm{LiFePO}_{4}$ (see Figure 7b). We suppose removal of structural inhomogeneities due to annealing process leads to such a dramatic improvement in electrochemical response from $\mathrm{LiFePO}_{4}$ films.

\section{CONCLUSIONS}

We have investigated the plasma spray deposited $\mathrm{LiFePO}_{4}$ films with carbon using electrochemical impedance spectroscopy, cyclic voltammetry and other techniques. Our studies show that plasma spray deposited $\mathrm{LiFePO}_{4}$ films possess porous structure and exhibit mixed crystallineamorphous microstructure. The impedance spectroscopy studies of as-deposited films indicate relative high impedance or sluggish kinetics. The as-deposited $\mathrm{LiFePO}_{4}$ films also show relative improvement upon compression. The compression induces favorable changes in the microstructure by reducing the porous structure. The microstructure of $\mathrm{LiFePO}_{4}$ films seem to be responsible for high impedance. The anneal treatment of $\mathrm{LiFePO}_{4}$ films improves the crystallinity and this results in better impedance characteristics. These studies indicate that the factors such as porosity and thermal stresses can affect the electrochemical properties of $\mathrm{LiFePO}_{4}$ films. The studies presented here give a unique insight into microstructure effects on the electrochemical properties of film based electrode materials and help in assessing their electrode characteristics. Considering the fact that thin films are of use 
for vital applications involving $\mathrm{Li}$ ion batteries, these studies could benefit the research community.

\section{REFERENCES}

[1] Tarascon JM, Armand M. Nature 2001; 414: 359.

[2] Hongwen H, Rui X, Jinxin F. Energies 2011; 4: 582.

[3] Rui X, Hongwen H, FengChun S, Kai Z. Online Estimation of Peak Power Capability of Li-lon Batteries in Electric Vehicles by a Hardware-in-Loop Approach. Energies 2012; 5: 1455. http://dx.doi.org/10.3390/en5051455

[4] Xuan Z, Ramesh G, Pravansu M. J Mater Chem A 2013; 1: 2757

[5] Nagaswetha P, Ramesh G, Pranvansu M. Electrochem Acta 2011; 56: 9851.

[6] Vikram V, Satishkumar BC, Jagit N, Pravansu M. J Power Sources 2011; 196: 10704

[7] Raghavender T, Ramesh G, Pranvansu M. J Power Sources 2012; 199: 270

[8] Zhang WJ. J Power Sources 2011; 196: 2962.
[9] Shi ZC, Attia A, Ye WL, Wang Q, Li YX, Yang Y. Electrochem Acta 2008; 53: 2665

[10] Zhang SS, Xu K, Jow TR. Electrochem Acta 2004; 49: 1057.

[11] Kimura A, et al, United States Patent 2010/0248025 A1, Electrolyte and secondary battery.

[12] Tsui YC, Doyle C, Clyne TW. Biomaterials 1998; 19: 2015.

[13] Zhou, X, Siman R, Lu L, Mohanty P. Argon atmospheric plasma sprayed hydroxyapatite/Ti composite coating for biomedical applications. Surf Coat Technol 2012; 207: 343 http://dx.doi.org/10.1016/i.surfcoat.2012.07.009

[14] Takeuchi S, Ito M, Takeda K. Modelling of residual stress in plasmasprayed coatings: Effect of substrate temperature. Surf Coat Techno 1990; 43/44: 426

http://dx.doi.org/10.1016/0257-8972(90)90094-S

[15] Khor KA, Gu YW. Effects of residual stress on the performance of plasma sprayed functionally graded $\mathrm{ZrO}_{2} / \mathrm{NiCoCrAlY}$ coatings. Mater Sci Eng 2000; A277: 64.

http://dx.doi.org/10.1016/S0921-5093(99)00565-1

[16] Zhou X, Mohanty P. Electrochemical behavior of cold sprayed hydroxyapatite/titanium composite in Hanks' solution. Electrochemica Acta 2000; 65: 134.

http://dx.doi.org/10.1016/i.electacta.2012.01.018 